\title{
Influence of Naturally Occurring Fiber (Switchgrass) Reinforcement on the Mechanical Properties of Epoxy Resin
}

\author{
Kunal Mishra ${ }^{1 *}$ and Libin $\mathrm{K}$ Babu ${ }^{2}$ \\ ${ }^{1}$ School of Mechanical and Aerospace Engineering, USA \\ ${ }^{2}$ Department of Integrated Engineering, USA \\ *Corresponding author: Kunal Mishra, School of Mechanical and Aerospace Engineering, Tulsa, USA
}

\begin{tabular}{|c|c|}
\hline ARTICLE INFO & ABSTRACT \\
\hline Received: 蔧 July 25, 2019 & In this present study, the natural occurring switchgrass (SG) is used as a reinforcement \\
\hline Published: 幽 August 01, 2019 & $\begin{array}{l}\text { in the epoxy resin. The obtained SG is cut into small sizes with dimension ranging between } \\
2 \text { and } 5 \mathrm{~cm} \text { and without any chemical treatment is directly reinforced in epoxy resin at }\end{array}$ \\
\hline $\begin{array}{l}\text { Citation: Kunal Mishra, Libin K Babu. } \\
\text { nfluence of Naturally Occurring Fiber } \\
\text { Switchgrass) Reinforcement on the }\end{array}$ & $\begin{array}{l}\text { show } 50 \% \text { and } 28.5 \% \text { increase in tensile modulus and strength respectively. These } \\
\text { modified properties of SG-epoxy composites have the potential for further use as a } \\
\text { structural composite. }\end{array}$ \\
\hline
\end{tabular}
Mechanical Properties of Epoxy Resin. Biomed J Sci \& Tech Res 20(2)-2019. BJSTR. MS.ID.003418.

\section{Introduction}

In the present era, lightweight composites are in great demand in various applications such as automobile, aerospace, as well as in recreational industries to enhance the efficiency and performance. Conventional carbon-based fillers including carbon nanotube [1,2], graphene [3], POSS [4-6] shows modification in epoxy-based composites, however, these fillers are expensive and hazardous to the environment. Recently, researchers are modifying composites using naturally occurring biodegradable materials such as jute or flax [7-12]. However, the cost of these materials is high thereby limiting the supply of these materials. In contrast, switchgrass (SG) is a self-seeding crop that can grow on small lands and also it requires low-input in terms of water and fertilizer to grow $[13,14]$. The advantage of using SG include less production costs and development of environmentally friendly products. There are only few studies where composites are reinforced with SG or where SG was used as a filler to enhance the properties of polypropylene [15].

The objective of this study is to employ untreated SG as a reinforcement in epoxy composites and to study its influence on the mechanical properties.

\section{Experimental}

\section{Materials}

SG was obtained from a research field at the University of Tulsa Campus. SG stems were manually separated from the mature crops. The stem was cut in the size between $2-5 \mathrm{~cm}$. The tensile properties of regular SG is given below:

\section{Tensile strength: $105 \pm 21.2 \mathrm{MPa}$}

Tensile modulus: $17.2 \pm 2.6 \mathrm{GPa}$

EPON 828, a diglycidyl ether bisphenol A based resin, and EPIKURE 3115, a polyamide based, curing agent was procured from Hexion (Houston, TX, USA).

\section{Fabrication}

Mixing of epoxy resin and SG were carried out in a magnetic stirrer at $50^{\circ} \mathrm{C}$ at $200 \mathrm{rpm}$ for $12 \mathrm{hr}$. The mixture was then cooled to room temperature and stoichiometric amount of amine-based curing agent (by 120\% wt. of epoxy) was added followed by mixing for an additional $10 \mathrm{~min}$. The mixture was then placed in 
a vacuum chamber for 15 minutes to remove gas bubbles hat may be introduced during mixing. Thereafter, the mixture was poured into an aluminum mold for casting, and cured at $100 \mathrm{C}$ for $1 \mathrm{hr}$. The wt.\% of SG in the epoxy resin varied from 0 to $25 \mathrm{wt} . \%$. The same procedure was used for preparing neat epoxy for comparison.

\section{Characterization}

The elastic modulus of the SG-epoxy nanocomposites was determined as per ASTM D-638 [16]. Samples were machined from cast plate with nominal dimension for Type 1 as per ASTM standard. Extensometer was placed within the gauge length to record the accurate strain measurement. Specimens were loaded in a displacement-controlled mode until failure, where the point of failure was identified from the peak load, $P$. The elastic modulus was determined from the stress-strain curve.

\section{Results and Discussion}

As shown in (Figure 1) we can clearly observe that inclusion of switchgrass increases the tensile strength. This increase in the strength is due to the higher elastic strength of SG compared to neat epoxy. The maximum value of strength was observed at $10 \mathrm{wt} . \%$ SG inclusion with an increase of $28.5 \%$ compared to epoxy resin. However, with increase in the value of SG in the epoxy resin the density of void increases due to lack of affinity between epoxy resin and SG. This increase in the void deteriorates the composites hence reduces the tensile strength.

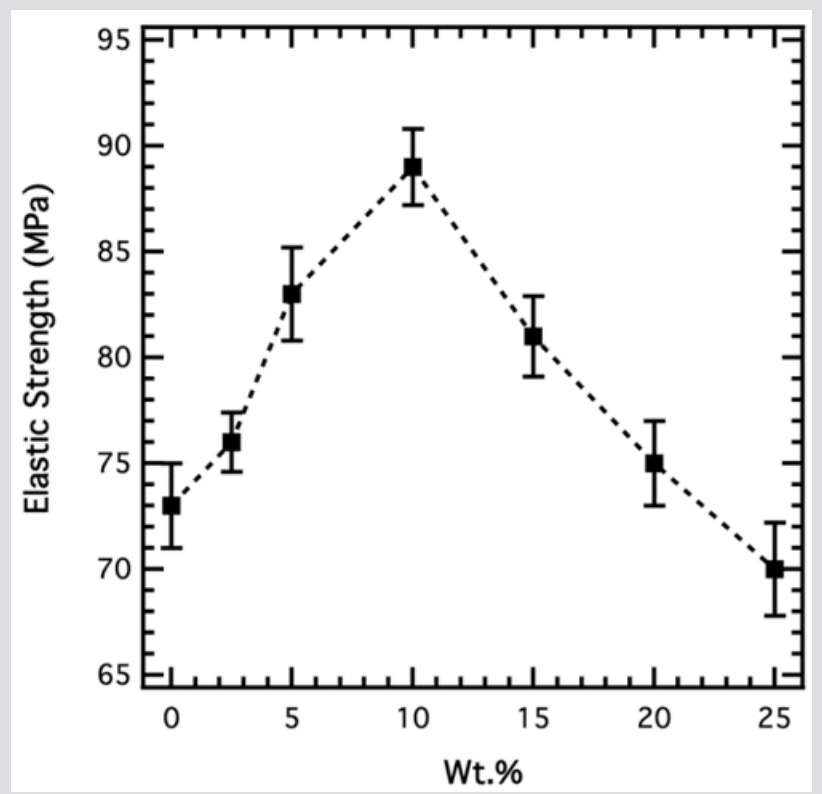

Figure 1: Variation in elastic strength of the composite as a function of SG content.

(Figure 2) illustrates the change in elastic modulus with the inclusion of SG at different wt. fractions. This is due to the higher modulus value of SG stem. We observed that $10 \mathrm{wt}$. \% of SG reinforcement increases the modulus value by $50 \%$ compared to neat epoxy. Nonetheless, increasing the SG content more than 10 wt. \% deteriorates the material and hence reduction in the modulus value was observed.

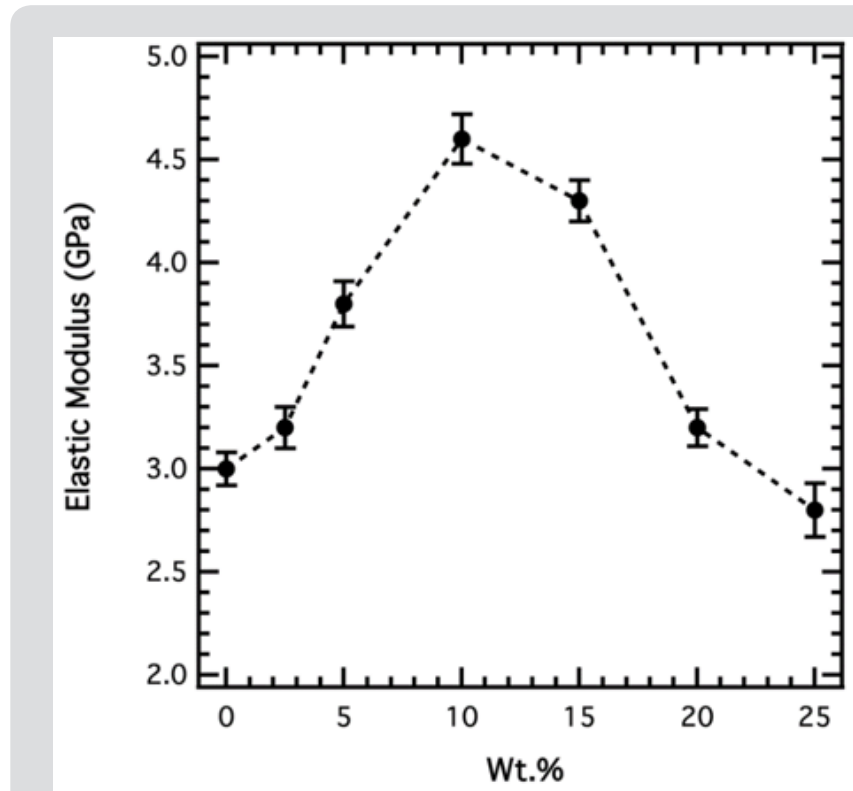

Figure 2: Changes in elastic strength as a function of wt. $\%$ of SG.

\section{Conclusion}

In this study we have used natural occurring fiber, switchgrass, as the reinforcement in epoxy composites. We have cut the grass into small size of 2-5 mm using precision cutter. The reinforcement of SG shows increase in the value of tensile strength and modulus by $28.5 \%$ and $50 \%$, respectively, compared to the neat resin at $10 \mathrm{wt} . \%$ inclusion. This increase in the tensile value is due to the higher tensile strength and modulus of the SG. Results shows that these naturally occurring inexpensive fiber can be used in composite to modify the properties for applications in various fields. Further investigation on chemical treatment of these SG is required to enhance its affinity with the epoxy resin and for further improvement in the properties.

\section{References}

1. Mishra Kunal, Raman P Singh (2019) Effect of APTMS modification on multiwall carbon nanotube reinforced epoxy nanocomposites. Composites Part B: Engineering 162: 425-432.

2. Rangari Vijaya K, Mohammad S Bhuyan, Shaik Jeelani (2010) Microwave processing and characterization of EPON 862/CNT nanocomposites. Materials Science and Engineering: B 168(1-3): 117-121.

3. Rafiee Mohammad A, Javad Rafiee, Zhou Wang, Huaihe Song, Zhong Zhen $\mathrm{Yu}$, et al. (2009) Enhanced mechanical properties of nanocomposites at low graphene content. ACS nano 3(12): 3884-3890.

4. Mishra Kunal, Raman P Singh (2018) Quantitative evaluation of the effect of dispersion techniques on the mechanical properties of polyhedral oligomeric silsesquioxane (POSS)-epoxy nanocomposites. Polymer Composites 39(4): E2445-E2453.

5. Mishra Kunal, Gajendra Pandey, Raman P Singh (2017) Enhancing the mechanical properties of an epoxy resin using polyhedral oligomeric silsesquioxane (POSS) as nano-reinforcement. Polymer Testing 62: 210218. 
6. Mishra Kunal, David Gidley, Raman P Singh (2019) Influence of self assembled compliant domains on the polymer network and mechanical properties of POSS-epoxy nanocomposites under cryogenic conditions. European Polymer Journal 116: 283-290.

7. Graupner Nina (2008) Application of lignin as natural adhesion promoter in cotton fibre-reinforced poly (lactic acid) (PLA) composites. Journal of Materials Science 43(15): 5222-5229.

8. Avella Maurizio, Gordana Bogoeva Gaceva, Aleksandra Bužarovska, Maria Emanuela Errico, Gennaro Gentile, et al. (2008) Poly (lactic acid)based biocomposites reinforced with kenaf fibers. Journal of Applied Polymer Science 108(6): 3542-3551.

9. Bax Benjamin, Jörg Müssig (2008) Impact and tensile properties of PLA/ Cordenka and PLA/flax composites. Composites science and technology 68(7-8): 1601-1607.

10. Bodros Edwin, Isabelle Pillin, Nicolas Montrelay, Christophe Baley (2007) Could biopolymers reinforced by randomly scattered flax fibre be used in structural applications? Composites Science and Technology 67(3-4): 462-470.

ISSN: 2574-1241

DOI: 10.26717/BJSTR.2019.20.003418

Kunal Mishra. Biomed J Sci \& Tech Res

(c) This work is licensed under Creative

Submission Link: https://biomedres.us/submit-manuscript.php
11. Huda MS, LT Drzal, M Misra, AK Mohanty (2006) Wood-fiber-reinforced poly (lactic acid) composites: evaluation of the physicomechanical and morphological properties. Journal of Applied Polymer Science 102(5): 4856-4869.

12. Wang Kuo Hsiung, Tzong Ming Wu, Yeng Fong Shih, Chien Ming Huang (2008) Water bamboo husk reinforced poly (lactic acid) green composites. Polymer Engineering \& Science 48(9): 1833-1839.

13. Goel K, R Eisner, G Sherson, T Radiotis, J Li (2000) Switchgrass: A potential pulp fibre source. Pulp and paper Canada ontario 101(6): 4147.

14. Law KN, BV Kokta, CB Mao (2001) Fibre morphology and soda-sulphite pulping of switchgrass. Bioresource technology 77(1): 1-7.

15. Zou Y, Xu H, Yang YJ (2010) Lightweight Polypropylene Composites Reinforced by Long Switchgrass Stems. Journal of Polymers and the Environment 18(4): 464-473.

16. (2003) ASTM D0638-14. Standard test method for tensile properties of plastics. ASTM International 08: 46-58.

$\begin{array}{ll}\text { BIOMEDICAL } & \text { Assets of Publishing with us } \\ \text { RESEARCHES } & \text { Global archiving of articles } \\ & \text { - Immediate, unrestricted online access } \\ & \text { - Rigorous Peer Review Process } \\ \end{array}$

